\title{
Diferentes concentrações de fungo micorrízico em mudas de três cultivares de
}

\section{maracujá}

\author{
Different concentrations of mycorrhizal fungi in seedlings of three cultivars of passion fruit \\ Diferentes concentraciones de hongos micorrizales en plantas de tres cultivares de maracuyá
}

Recebido: 04/02/2021 | Revisado: 11/02/2021 | Aceito: 16/02/2021 | Publicado: 24/02/2021

\author{
João Carlos Santos de Andrade \\ ORCID: https://orcid.org/0000-0001-9790-1275 \\ Instituto Federal de Educação, Ciência e Tecnologia do Tocantins, Brasil \\ E-mail: joaocarlosandrade@outlook.com \\ Geslanny Oliveira Sousa \\ ORCID: https://orcid.org/0000-0003-3537-9543 \\ Universidade Estadual da Região Tocantina do Maranhão, Brasil \\ E-mail: geslannyoliveira1@gmail.com \\ Jossimara Ferreira Damascena \\ ORCID: https://orcid.org/0000-0002-7020-8507 \\ Universidade Federal do Tocantins, Brasil \\ E-mail: jossi_agro@hotmail.com \\ Juliana Andrade Pereira \\ ORCID: https://orcid.org/0000-0003-4131-0489 \\ Universidade Estadual da Região Tocantina do Maranhão, Brasil \\ E-mail: juliana_andradep@hotmail.com
}

\begin{abstract}
Resumo
A utilização da micorriza é considerada uma alternativa para a redução do uso de insumos na agricultura, devido aos seus efeitos benéficos no desenvolvimento de plantas de interesse agronômico, florestal, hortícola e pastoril. O trabalho tem como objetivo avaliar a produção de mudas de três cultivares de maracujá submetidas a diferentes concentrações de fungo micorrízico da espécie Gigaspora candida. Para isto, conduziu-se um experimento em delineamento de blocos casualizados em esquema fatorial de $3 \times 4$, com três cultivares de maracujá e quatro concentrações de fungo, com três repetições em cada tratamento. Foi usado as seguintes cultivares de maracujá: Gigante Amarelo; Rubi do Cerrado e Sol do Cerrado, cada cultivar foi inoculada com quatro densidades de FMA (0, 100, 200 e 300 esporos.planta $^{-1}$ ) da espécie Gigaspora candida. A altura da planta nas mudas no tratamento com concentração 0 esporos.planta ${ }^{-1}$ apresentou maiores valores comparado a 100 esporos.planta ${ }^{-1}$ e tendem a aumentar a partir da concentração de 200 esporos.planta ${ }^{-1}$ com o fungo Gigaspora candida. Para o número de folhas, as cultivares Gigante amarelo e Sol do Cerrado mostram tendência em aumentar a quantidade em todas as densidades de FMA testadas. A $c v$. Rubi do Cerrado apresentou o menor número de folhas em todas as doses testadas.
\end{abstract}

Palavras-chave: Gigaspora candida; Passiflora ssp.; Simbiose.

\begin{abstract}
The use of mycorrhiza has been considered an alternative to reduce the use of inputs in agriculture, due to it's beneficial effects on the development of plants of agronomic, forest, horticultural and pastoral interest. The work aims to evaluate the production of seedlings of three passion fruit cultivars submitted to different concentrations of mycorrhizal fungus of the species Gigaspora candida. For this, an experiment was carried out in a randomized block design in a $3 \times 4$ factorial scheme, with three cultivars of passion fruit and four concentrations of fungus, with three replicates in each treatment. The following passion fruit cultivars were used: Gigante Amarelo; Rubi do Cerrado and Sol do Cerrado, each cultivar was inoculated with four densities of FMA $\left(0,100,200\right.$ and 300 spores.plant $\left.^{-1}\right)$ of the $^{-1}$ species Gigaspora candida. The plant height in the seedlings in the treatment with concentration 0 spores.plant ${ }^{-1}$ showed higher values compared to 100 spores.plant $^{-1}$ and tend to increase from the concentration of 200 spores.plant $^{-1}$ with the fungus Gigaspora candida. For the number of leaves, the cultivars Gigante Amarelo and Sol do Cerrado show a tendency to increase the amount in all densities of AMF tested. The $c v$. Rubi do Cerrado had the lowest number of leaves in all doses tested.
\end{abstract}

Keywords: Gigaspora candida; Passiflora ssp.; Symbiosis.

\section{Resumen}

El uso de micorrizas se considera una alternativa para reducir el uso de insumos en la agricultura, debido a sus efectos beneficiosos sobre el desarrollo de plantas de interés agronómico, forestal, hortícola y pastoril. El trabajo tiene como objetivo evaluar la producción de plántulas de tres cultivares de maracuyá sometidos a diferentes concentraciones de 
hongo micorrízico de la especie Gigaspora candida. Para ello, se realizó un experimento en un diseño de bloques al azar en un esquema factorial de $3 \times 4$, con tres cultivares de maracuyá y cuatro concentraciones de hongo, con tres réplicas en cada tratamiento. Se utilizaron los siguientes cultivares de maracuyá: Gigante Amarelo; Rubi do Cerrado y Sol do Cerrado, cada cultivar fue inoculado con cuatro densidades de FMA $\left(0,100,200\right.$ y 300 esporas.planta $\left.^{-1}\right)$ de la especie Gigaspora candida. La altura de planta en las plántulas en el tratamiento con concentración 0 esporas.planta ${ }^{-1}$ mostró valores más altos en comparación con 100 esporas.planta ${ }^{-1}$ y tienden a aumentar a partir de la concentración de 200 esporas.planta ${ }^{-1}$ con el hongo Gigaspora candida. Para el número de hojas, los cultivares Gigante Amarelo y Sol do Cerrado muestran una tendencia a aumentar la cantidad en todas las densidades de HMA ensayadas. El $c v$. Rubi do Cerrado mostró el menor número de hojas en todas las dosis probadas.

Palabras clave: Gigaspora candida; Passiflora ssp.; Simbiosis.

\section{Introdução}

O Maracujazeiro, da família das Passifloráceas, é uma vigorosa trepadeira sublenhosa e tem grande vigor vegetativo. As folhas são pecioladas, estipuladas, profundamente trilobadas, serreadas e glabras. As flores são axilares, solitárias, brancas com franja roxa, tem em média cinco centímetros de diâmetro. $O$ fruto é uma baga com 5 a 7 centímetros de diâmetro, geralmente amarelo, salpicada de púrpura enegrecida, quando madura (Gomes, 2012).

O Brasil vem se destacando no cenário mundial quanto à produção de maracujá, chegou a produzir 593.429 toneladas no ano de 2019, em uma área de 41.584 ha, com produtividade de 14,27 t.ha-1 (IBGE, 2019). No Tocantins, a produção chegou a 840 toneladas em uma área de 84 ha, com rendimento médio de 10,00 t.ha ${ }^{-1}$. (IBGE, 2019).

Um projeto importante na região é o Polo de Fruticultura Irrigada São João (Porto Nacional - TO), que estimula a produção de diversas culturas agrícolas, entre elas a do maracujá, esse projeto tem uma produção média de 40 toneladas.ha $^{-1}$ (Portal Tocantins, 2019). A cultura ainda está tomando espaço na região e as adversidades devem ser contornadas, para isso, cultivares mais adaptáveis ao ecótipo estão sendo selecionadas e lançadas no mercado (Embrapa, 2018).

Na procura de incrementar e impulsionar a expansão da cultura, é buscado avaliar alternativas de produção que também haja redução nos custos do cultivo. Para tanto, o emprego de fungos micorrízicos arbusculares (FMA's) apresenta-se como uma alternativa promissora, sendo atualmente um método estudado e difundido na produção de mudas frutíferas, com promessas de plantas precoces e vigorosas (Silveira, et al., 2003).

As micorrizas são associações entre raízes de plantas e determinados fungos do solo, presentes em mais de $90 \%$ das famílias vegetais e dispersa por todo o planeta (Hoffmann \& Lucena, 2006). A utilização da micorriza é uma alternativa para a redução no uso de insumos (fertilizantes e pesticidas) na agricultura, pois confere benefícios ao desenvolvimento de plantas de interesse agronômico, florestal, hortícola e pastoril. Essas plantas micorrizadas apresentam uma maior absorção de macro e micronutrientes, resultando em maior acúmulo de matéria seca (Matos, Silva \& Lima, 1999).

Cavalcante, et al., (2002), ao trabalhar com produção de mudas de maracujá, afirmam que os FMA's são promissores em proporcionar maior vigor e reduzirem o tempo necessário para o transplantio de mudas de maracujazeiro para o campo, acarretando respostas na altura, diâmetro do caule, número de folhas e biomassa da raiz.

Com tudo, ainda é necessário que haja mais avaliações em relação a simbiose do fungo micorrízico e o maracujá, assim, é importante compreender a evolução, ecologia e relações biológicas desta associação. Desta forma, esta pesquisa tem como objetivo, avaliar a produção de mudas de três cultivares de maracujá submetidas a diferentes concentrações de fungo micorrízico da espécie Gigaspora candida.

\section{Metodologia}

\subsection{Caracterização e localização da área do experimento}

O experimento foi conduzido no Instituto Federal de Educação, Ciência e Tecnologia do Tocantins - IFTO/Campus Araguatins na cidade de Araguatins - TO, nas coordenadas geográficas de latitude $05^{\circ} 38^{\prime} 32^{\prime \prime}$ S e longitude $48^{\circ} 04^{\prime}$ ' 13" W, no 
mês de outubro de 2019 a janeiro de 2020.

O clima característico da região, segundo a classificação de Köppen-Geiger, é do tipo Aw, caracterizado como clima quente com inverno seco e verão chuvoso. A precipitação média anual é de $1500 \mathrm{~mm}$, temperatura média de $28,5^{\circ} \mathrm{C}$ e altitude de 103m (INMET, 2016). A experimentação foi conduzida no viveiro do IFTO no campus Araguatins.

\subsection{Tratamento e delineamento experimental}

Conduziu-se o experimento em delineamento de blocos casualizado (DBC), em esquema fatorial de $3 \times 4$, com três cultivares de maracujá, quatro concentrações de fungos, sendo três repetições em cada tratamento, resultando 36 parcelas. Foi usado as seguintes cultivares de maracujá adquiridas da empresa Agrocinco: Gigante Amarelo; Rubi do Cerrado e Sol do Cerrado, cada cultivar foi inoculada com quatro densidades de fungo micorrízico arbuscular (0, 100, 200 e 300 esporos.planta-

$\left.{ }^{1}\right)$ da espécie Gigaspora candida.

\subsection{Semeadura}

As mudas de maracujá foram semeadas em bandejas com 200 células contendo areia e substrato comercial (1:1 - v/v). As plântulas com duas folhas definitivas foram transferidas para recipientes plásticos de $200 \mathrm{ml}$, contendo $180 \mathrm{ml}$ de solo onde foi adicionado, na região da raiz, solo inóculo contendo os esporos dos FMA.

\subsection{Preparo do solo inóculo}

Os fungos foram obtidos da Embrapa Agrobiologia, os esporos estavam contidos em solo inóculo, onde a cada 6,25 g de solo continha 100 esporos do fungo. A pesagem foi feita para que se pudesse fracionar o solo inóculo e ter com exatidão a quantia a adicionar em cada tratamento.

No momento da transferência das mudas para os copos, descartáveis de $200 \mathrm{ml}$, foi adicionado na região da raiz os esporos do fungo e logo após foi feita a transferência das plântulas, depositando $6,25 \mathrm{~g}$ de esporos para o tratamento de 100 esporos.planta $^{-1} ; 12,5 \mathrm{~g}$ de esporos para o tratamento de 200 esporos.planta $^{-1} \mathrm{e} ; 18,75 \mathrm{~g}$ de esporos para o tratamento de 300 esporos.planta ${ }^{-1}$ puros. Após 15 dias as plântulas foram transferidas para sacos de polietileno preto contendo solo misturado com casca de arroz carbonizado na proporção 3:1, mantendo uma plântula.saco-1.

\subsection{Variáveis analisadas}

Ao final de 90 dias após a semeadura, foram tomadas medidas das plantas a campo: altura da planta (AP), medindo a partir do solo até a inserção da última folha, tendo auxílio de uma régua métrica; diâmetro do caule (DC), medido na altura de $3 \mathrm{~cm}$ do solo, com auxílio de um paquímetro eletrônico; e número de folhas (NF).

O material foi coletado e levado para o laboratório de bromatologia do IFTO, onde foram avaliados: comprimento de raiz (CR), tendo auxílio de uma régua métrica; massa fresca da parte aérea (MFPA); massa seca da parte aérea (MSPA); massa fresca das raízes (MFR); e massa seca das raízes (MSR), utilizando uma balança de precisão para as quatro últimas avaliações.

A parte aérea e as raízes das plantas foram picadas e colocadas em estufa de circulação de ar $\left(65^{\circ} \mathrm{C}\right)$ por 72 horas, para determinação da biomassa seca. O material foi cortado em partes menores e colocados em sacos de papel com pequenos furos.

\subsection{Análises estatísticas}

Os resultados obtidos foram submetidos à análise de variância, pelo teste F. Os dados qualitativos foram submetidos ao teste de Tukey a $1 \%$ e $5 \%$ de probabilidade e foram aceitas as equações significativas até $5 \%$ de probabilidade pelo teste $\mathrm{F}$, com o maior coeficiente de determinação (R2), utilizando-se o programa estatístico Sisvar versão 5.6 (Ferreira, 2014). 


\section{Resultados e Discussão}

Nos parâmetros avaliados, é possível notar o efeito significativo ou não significativo para o fator cultivar em função da densidade de esporos de fungos micorrízicos arbusculares (FMA) da espécie Gigaspora candida (Tabela 1 e 2).

Tabela 1: Valores da análise de variância para os parâmetros de altura da planta (AP), diâmetro do caule (DC), número de folhas (NF) e comprimento de raiz (CR) para as cultivares de maracujá em razão da inoculação do fungo Gigaspora candida.

\begin{tabular}{lccccc}
\hline Fonte de Variação & GL & $\mathbf{A P}(\mathbf{c m})$ & $\mathbf{D C}(\mathbf{m m})$ & $\mathbf{N F}$ & $\mathbf{C R}(\mathbf{c m})$ \\
\hline Cultivar & 2 & $20,934^{* *}$ & $0,143^{\mathrm{ns}}$ & $4,292^{*}$ & $14,420^{\mathrm{ns}}$ \\
Dose & 3 & $8,141^{\mathrm{ns}}$ & $0,008^{\mathrm{ns}}$ & $0,057^{\mathrm{ns}}$ & $33,336^{\mathrm{ns}}$ \\
Cultivar X Dose & 6 & $4,215^{\mathrm{ns}}$ & $0,037^{\mathrm{ns}}$ & $0,287^{\mathrm{ns}}$ & $3,392^{\mathrm{ns}}$ \\
\hline Bloco & 2 & $0,645^{\mathrm{ns}}$ & $0,015^{\mathrm{ns}}$ & $0,470^{\mathrm{ns}}$ & $0,512^{\mathrm{ns}}$ \\
Resíduo & 22 & 3,109 & 0,045 & 0,185 & 13,828 \\
Total & 35 & - & - & - & - \\
\hline Média & - & 14.72 & 2,89 & 9,93 & 29,96 \\
\hline CV $(\%)$ & - & 11.98 & 7,37 & 4,34 & 12,41 \\
\hline ns - não significativo. *, ** - significativo a 5\% e 1\% de probabilidade, respectivamente. Fonte: Autores.
\end{tabular}

Tabela 2: Valores da análise de variância para os parâmetros de massa fresca da parte aérea (MFPA), massa seca da parte aérea (MSPA), massa fresca das raízes (MFR) e massa seca das raízes (MSR) para as cultivares de maracujá em razão da inoculação do fungo Gigaspora candida.

\begin{tabular}{lccccc}
\hline Fonte de Variação & GL & MFPA (g) & MFR (g) & MSPA (g) & MSR (g) \\
\hline Cultivar & 2 & $2,695^{\mathrm{ns}}$ & $0,223^{\mathrm{ns}}$ & $0,076^{\mathrm{ns}}$ & $0,002^{\mathrm{ns}}$ \\
Dose & 3 & $2,314^{\mathrm{ns}}$ & $0,103^{\mathrm{ns}}$ & $0,063^{\mathrm{ns}}$ & $0,010^{\mathrm{ns}}$ \\
Cultivar X Dose & 6 & $2,004^{\mathrm{ns}}$ & $0,206^{\mathrm{ns}}$ & $0,064^{\mathrm{ns}}$ & $0,007^{\mathrm{ns}}$ \\
\hline Bloco & 2 & $0,067^{\mathrm{ns}}$ & $1,057^{*}$ & $0,004^{\mathrm{ns}}$ & $0,002^{\mathrm{ns}}$ \\
Resíduo & 22 & 2,214 & 0,197 & 0,070 & 0,009 \\
Total & 35 & - & - & - & - \\
\hline Média & - & 7,63 & 2,02 & 1,419 & 0,426 \\
\hline CV $(\%)$ & - & 19,49 & 21,97 & 18,74 & 22,31 \\
\hline
\end{tabular}

ns - não significativo. *, ** - significativo a 5\% e $1 \%$ de probabilidade, respectivamente. Fonte: Autores.

\subsection{Altura da planta e diâmetro do caule}

Há diferença significativa para desdobramento cultivar na dose de 200 esporos.planta $^{-1}$ para altura de planta (AP). Neste nível, a $c v$. Gigante amarelo mostrou maior desenvolvimento em altura em relação à $c v$. Rubi do cerrado e a $c v$. Sol do cerrado (Tabela 3). A cv. Gigante amarelo apresentou a maior tendência, com média de AP $(15,68 \mathrm{~cm})$ dentre as cultivares, com e sem a utilização de FMA. 
Nos tratamentos com concentração de 0 esporos.planta ${ }^{-1}(14,36 \mathrm{~cm})$, apresentou valor superior ao tratamento com 100 esporos.planta ${ }^{-1}(13,59 \mathrm{~cm})$ e inferior as demais concentrações, 200 e 300 esporos.planta $^{-1}$, porém não houve diferença estatística.

Cavalcante, et al., (2001) em seu trabalho, verificando a resposta fisiológica em mudas de maracujazeiro amarelo inoculadas com três espécies de fungos micorrízicos arbusculares e submetidas a estresse hídrico iniciado aos 40 dias após a inoculação, não obteve resultado significativo, porém mostraram-se benéficas, apresentando ganhos na altura de $8 \mathrm{~cm}, 4 \mathrm{~cm}$ e $8 \mathrm{~cm}$, respectivamente, para G. albida, G. margarita e G. etunicatum, enquanto as não inoculadas não cresceram, continuaram com $8,2 \mathrm{~cm}$ antes e depois do estresse.

Tabela 3: Desdobramento de cultivar de maracujá em razão da inoculação do fungo Gigaspora candida dentro de cada nível de dose de altura da planta (AP) e diâmetro do caule (DC) aos 90 dias após a semeadura.

\begin{tabular}{|c|c|c|c|c|c|}
\hline \multirow{2}{*}{ Cultivar } & \multicolumn{4}{|c|}{ Densidades de FMA (esporos.planta $^{-1}$ ) } & \multirow{2}{*}{ Média } \\
\hline & $\mathbf{0}$ & 100 & 200 & 300 & \\
\hline & \multicolumn{4}{|c|}{ Altura da planta (cm) } & \\
\hline Gigante Amarelo & $13,77 \mathrm{a}$ & $14,15 \mathrm{a}$ & $18,32 \mathrm{a}$ & $16,48 \mathrm{a}$ & 15,68 \\
\hline Rubi do Cerrado & $14,08 \mathrm{a}$ & $12,23 \mathrm{a}$ & $13,49 \mathrm{~b}$ & $13,05 \mathrm{a}$ & 13,21 \\
\hline Sol do Cerrado & $15,24 \mathrm{a}$ & $14,40 \mathrm{a}$ & $15,58 \mathrm{ab}$ & $15,84 \mathrm{a}$ & 15,26 \\
\hline \multirow[t]{2}{*}{ Média } & 14,36 & 13,59 & 15,79 & 15,12 & \\
\hline & \multicolumn{4}{|c|}{ Diâmetro do caule (mm) } & \\
\hline Gigante Amarelo & $2,74 \mathrm{a}$ & $2,87 \mathrm{a}$ & $3,01 \mathrm{a}$ & $2,99 \mathrm{a}$ & 2,90 \\
\hline Rubi do Cerrado & $2,91 \mathrm{a}$ & $2,67 \mathrm{a}$ & $2,72 \mathrm{a}$ & $2,80 \mathrm{a}$ & 2,77 \\
\hline Sol do Cerrado & $3,00 \mathrm{a}$ & $3,01 \mathrm{a}$ & $3,02 \mathrm{a}$ & $2,95 \mathrm{a}$ & 2,99 \\
\hline Média & 2,88 & 2,85 & 2,92 & 2,91 & \\
\hline
\end{tabular}

Letras minúsculas iguais correspondem a comparação entre doses (colunas) não diferem entre si no teste Tukey (P $\leq 0,05)$. Fonte: Autores.

$\mathrm{Na}$ média geral para as cultivares em DC, a $c v$. Sol do cerrado apresentou 2,99 mm de espessura, seguindo por $c v$. Gigante amarelo e rubi do cerrado com respectivamente $2,90 \mathrm{~mm}$ e 2,77 mm. Na média das concentrações de FMA em DC, apresentou comportamento semelhante ao do parâmetro AP. Para os tratamentos com concentração de 0 esporos.planta ${ }^{-1}$ houve menor tendência $(2,88 \mathrm{~mm})$ porém, não houve diferença estatística comparado com as demais concentrações. Isso mostra que a ausência ou presença do fungo pode não influenciar o diâmetro de caule.

Cavalcante, et al., (2002), não encontraram efeito significativo do número de esporos por planta para a variável diâmetro de caule em mudas de maracujazeiro, o mesmo encontrando 2,16 mm e 1,83 mm aos 30 dias; 2,97 mm e 2,70 mm aos 40 dias; 3,59 mm e 3,50 mm aos 50 dias para a espécies G. albida e G. margarita, respectivamente.

\subsection{Número de folhas e comprimento de raiz}

Há diferença significativa para desdobramento cultivar dentro dose em todos os níveis para número de folhas (NF). Podemos verificar na Tabela 4, as cultivares Gigante amarelo e Sol do cerrado mostram tendência a aumentar em todas as densidades de FMA testadas. A $c v$. Rubi do Cerrado apresentou o menor número de folhas em todas as doses testadas, sua média geral foi de 9,26 folhas aos 90 dias após a semeadura.

A produção de folhas juntamente com a sua área foliar representa a face fotossinteticamente ativa da planta, e está ligada ao crescimento vegetal, portanto incrementos maiores resultam no direcionamento do potencial para aumento da biomassa da planta (Cavalcante, et al., 2001). 
O desenvolvimento do maracujazeiro foi beneficiado pela inoculação com FMA, enquanto as plantas não inoculadas restringiram a produção de folhas e a expansão foliar, em média as plantas inoculadas tiveram área de $212,7 \mathrm{~cm}^{2}$, enquanto as não inoculadas apenas $3 \mathrm{~cm}^{2}$ (Cavalcante, et al., 2001).

Tabela 4: Desdobramento de cultivar de maracujá em razão da inoculação do fungo Gigaspora candida dentro de cada nível de dose de número de folhas (NF) e comprimento de raiz (CR) aos 90 dias após a semeadura.

\begin{tabular}{|c|c|c|c|c|c|}
\hline \multirow{2}{*}{ Cultivar } & \multicolumn{4}{|c|}{ Densidades de FMA (esporos.planta $^{-1}$ ) } & \multirow{2}{*}{ Média } \\
\hline & $\mathbf{0}$ & 100 & 200 & 300 & \\
\hline & \multicolumn{4}{|c|}{ Número de folhas } & \\
\hline Gigante Amarelo & $10,16 \mathrm{a}$ & $10,45 \mathrm{a}$ & $10,62 \mathrm{a}$ & $10,45 \mathrm{a}$ & 10,42 \\
\hline Rubi do Cerrado & $9,16 \mathrm{~b}$ & $9,29 \mathrm{~b}$ & $9,12 \mathrm{~b}$ & $9,50 \mathrm{~b}$ & 9,26 \\
\hline Sol do Cerrado & $10,62 \mathrm{a}$ & $9,70 \mathrm{ab}$ & $10,12 \mathrm{a}$ & $10,00 \mathrm{ab}$ & 10,11 \\
\hline \multirow[t]{2}{*}{ Média } & 9,98 & 9,81 & 9,95 & 9,98 & \\
\hline & \multicolumn{4}{|c|}{ Comprimento de raiz (cm) } & \\
\hline Gigante Amarelo & $26,10 \mathrm{a}$ & $30,21 \mathrm{a}$ & $27,51 \mathrm{a}$ & $31,83 \mathrm{a}$ & 28,91 \\
\hline Rubi do Cerrado & $28,36 \mathrm{a}$ & $30,56 \mathrm{a}$ & 28,63 a & 31,96 a & 29,87 \\
\hline Sol do Cerrado & $28,31 \mathrm{a}$ & 32,85 a & 31,60 a & 31,65 a & 31,10 \\
\hline Média & 27,59 & 31,20 & 29,24 & 31,81 & \\
\hline
\end{tabular}

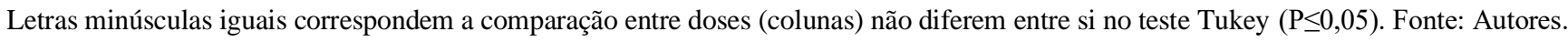

Pode-se observar o efeito da inoculação de FMA no volume radicular, quando comparados ao controle (0 esporos.planta ${ }^{-1}$ ), há tendência de um maior volume de raízes a medida em que aumentasse a concentração de esporos de FMA em média. A $c v$. Sol do cerrado apresentou o maior CR dentre as cultivares, com 31,10 cm, seguido pela $c v$. Rubi do Cerrado e Gigante Amarelo com, respectivamente, $29,87 \mathrm{~cm}$ e 28,91 cm, porém, para essa variável, não houve diferença estatística.

A simbiose de plantas com fungos micorrízicos arbusculares torna possível o estabelecimento de mudas em solos com condições sub-ótimas devido a uma rede de hifas extracelulares que aumentam a área de absorção das raízes e a melhoria nos aspectos nutricionais da planta que adquirem maior capacidade de sobrevivência a condições adversas (Boff \& Mello, 2009).

\subsection{Massa fresca e seca da parte aérea}

Não houve diferença estatística para nenhum nível do desdobramento cultivar x dose para MFPA e MSPA (Tabela 5). A maior média de MFPA em relação à densidade de esporos de FMA encontrasse na densidade de 200 esporos.planta ${ }^{-1}$, enquanto a menor foi verificada na densidade 100 esporos.planta ${ }^{-1}$. Em relação à resposta das cultivares testada, a $c v$. Sol do cerrado obteve 8,25 g de MFPA na média geral com todas as doses utilizadas, seguida pela $c v$. Gigante amarelo com 7,33 g. 
Tabela 5: Desdobramento de cultivar de maracujá em razão da inoculação do fungo Gigaspora candida dentro de cada nível de dose: massa fresca da parte aérea (MFPA); massa seca da parte aérea (MSPA) aos 90 dias após a semeadura.

\begin{tabular}{|c|c|c|c|c|c|}
\hline \multirow{2}{*}{ Cultivar } & \multicolumn{4}{|c|}{ Densidades de FMA (esporos.planta ${ }^{-1}$ ) } & \multirow{2}{*}{ Média } \\
\hline & $\mathbf{0}$ & 100 & 200 & 300 & \\
\hline & \multicolumn{4}{|c|}{ Massa fresca da parte aérea (g) } & \\
\hline Gigante Amarelo & $6,19 \mathrm{a}$ & $6,75 \mathrm{a}$ & $8,60 \mathrm{a}$ & $7,79 \mathrm{a}$ & 7,33 \\
\hline Rubi do Cerrado & $8,13 \mathrm{a}$ & $6,45 \mathrm{a}$ & $7,37 \mathrm{a}$ & $7,25 \mathrm{a}$ & 7,30 \\
\hline Sol do Cerrado & $8,43 \mathrm{a}$ & $7,58 \mathrm{a}$ & $8,10 \mathrm{a}$ & 8,89 a & 8,25 \\
\hline \multirow[t]{2}{*}{ Média } & 7,58 & 6,92 & 8,02 & 7,97 & \\
\hline & \multicolumn{4}{|c|}{ Massa seca da parte aérea $(\mathrm{g})$} & \\
\hline Gigante Amarelo & $1,17 \mathrm{a}$ & $1,25 \mathrm{a}$ & $1,56 \mathrm{a}$ & $1,37 \mathrm{a}$ & 1,33 \\
\hline Rubi do Cerrado & $1,58 \mathrm{a}$ & $1,15 \mathrm{a}$ & $1,39 \mathrm{a}$ & $1,50 \mathrm{a}$ & 1,40 \\
\hline Sol do Cerrado & $1,51 \mathrm{a}$ & $1,48 \mathrm{a}$ & $1,49 \mathrm{a}$ & $1,51 \mathrm{a}$ & 1,49 \\
\hline Média & 1,42 & 1,29 & 1,48 & 1,46 & \\
\hline
\end{tabular}

Letras minúsculas iguais correspondem a comparação entre doses (colunas) não diferem entre si no teste Tukey (P $\leq 0,05)$. Fonte: Autores.

Para a MSPA, obteve-se 18,74 \%; 18,62\%; 18,46\%; e 18,42\% para acúmulo de matéria de seca (MS), para: 0; 100; 200; e 300 esporos.planta ${ }^{-1}$, respectivamente. À medida que aumenta a dose, há uma tendência ao decréscimo do acúmulo de matéria seca. Em relação às cultivares, a $c v$. Rubi do Cerrado acumulou 19,20\% de MS, seguida pela $c v$. Gigante Amarelo $(18,28 \% \mathrm{MS})$ e $c v$. Sol do cerrado (18,20\% MS).

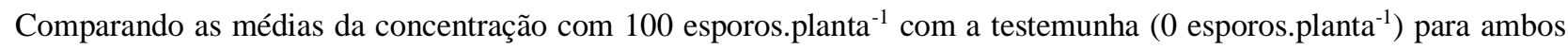
parâmetros, não ocorre incremento na massa das mudas, mas sim decréscimo de -0,65 g para MFPA e -0,12 g para MSPA.

A biomassa seca da parte aérea e a área foliar atingiram valores máximos com 300 esporos.planta ${ }^{-1}$, independente da espécie da FMA. Apesar da ausência da especificidade na simbiose micorrízica arbuscular, a eficiência é controlada geneticamente, sendo afetada pela espécie da planta e do fungo, além das condições ambientais (Cavalcante, et al., 2002).

Porém, em concentrações maiores que 100 esporos.planta ${ }^{-1}$ utilizadas nesta pesquisa, ocorre acréscimos de $0,44 \mathrm{~g}$ e 0,39 g para 200; 300 esporos.planta ${ }^{-1}$, respectivamente, em MFPA quando comparadas às mudas não inoculadas. Vitorazi filho, et al., (2012) em seu trabalho, utilizam a espécie de FMA Gigaspora margarita, na qual promoveu incrementos de $1500 \%$ em relação à massa seca da parte aérea, além de $937 \%$ no que se refere à área foliar, em 25 comparação com mudas não inoculadas com FMAs em mudas de maracujazeiro-doce.

A relação entre a concentração de fósforo $(\mathrm{P})$ na planta e a resposta em crescimento de plantas micorrizadas é determinada por processos opostos, um benéfico devido ao aumento na absorção de P do solo causado pelo fungo, e outro detrimental, provocado pela utilização de produtos fotossintetizados pelo fungo. O balanço dos dois processos normalmente resulta em maior crescimento das plantas colonizadas, mas pode também resultar em redução (Silveira, et al., 2003).

\subsection{Massa fresca e seca das raízes}

Não houve diferença estatística em nenhum nível do desdobramento cultivar x dose para MFR e MSR. Para a MFR, observa-se que na dose de 100 esporos.planta $^{-1}$ foi inferior ao tratamento com 0 esporos.planta ${ }^{-1}$, o maior valor de massa encontra-se na dose de 200 esporos.planta ${ }^{-1}$ com 2,13 g (tabela 6). O incremento no crescimento das mudas, proporcionado por G. albida, alcançou $1.937 \%$ na biomassa fresca da raiz em relação ao controle não inoculado no trabalho de Silva, et al., (2004).

Em relação à resposta pelas cultivares testadas, a $c v$. Sol do cerrado apresentou $2,17 \mathrm{~g}$ de massa radicular na média geral com todas as doses utilizadas. Seguida $c v$. Rubi do cerrado com 1,97 g. Agra (2007) obteve 5,95 g para matéria fresca da 
raiz utilizando a espécie Gigaspora albidaem em mudas de maracujá aos 90 dias de inoculação, porém, a espécie Scutelospora heterograma teve o melhor destaque para essa variável $(6,89 \mathrm{~g})$.

Tabela 6: Desdobramento de cultivar de maracujá em razão da inoculação do fungo Gigaspora candida dentro de cada nível de dose: massa fresca das raízes (MFR); e massa seca das raízes (MSR) aos 90 dias após a semeadura.

\begin{tabular}{|c|c|c|c|c|c|}
\hline \multirow{2}{*}{ Cultivar } & \multicolumn{4}{|c|}{ Densidades de FMA (esporos.planta $^{-1}$ ) } & \multirow{2}{*}{ Média } \\
\hline & $\mathbf{0}$ & 100 & 200 & 300 & \\
\hline & \multicolumn{4}{|c|}{ Massa fresca das raízes (g) } & \\
\hline Gigante Amarelo & $1,52 \mathrm{a}$ & $2,02 \mathrm{a}$ & $2,16 \mathrm{a}$ & $1,91 \mathrm{a}$ & 1,90 \\
\hline Rubi do Cerrado & $2,29 \mathrm{a}$ & $1,64 \mathrm{a}$ & $2,01 \mathrm{a}$ & $1,95 \mathrm{a}$ & 1,97 \\
\hline Sol do Cerrado & $2,09 \mathrm{a}$ & $2,01 \mathrm{a}$ & $2,22 \mathrm{a}$ & $2,36 \mathrm{a}$ & 2,17 \\
\hline \multirow[t]{2}{*}{ Média } & 1,96 & 1,89 & 2,13 & 2,07 & \\
\hline & \multicolumn{4}{|c|}{ Massa seca das raízes (g) } & \\
\hline Gigante Amarelo & $0,35 \mathrm{a}$ & $0,40 \mathrm{a}$ & $0,42 \mathrm{a}$ & $0,49 \mathrm{a}$ & 0,415 \\
\hline Rubi do Cerrado & $0,47 \mathrm{a}$ & $0,33 \mathrm{a}$ & $0,43 \mathrm{a}$ & $0,43 \mathrm{a}$ & 0,415 \\
\hline Sol do Cerrado & $0,48 \mathrm{a}$ & $0,40 \mathrm{a}$ & $0,43 \mathrm{a}$ & $0,44 \mathrm{a}$ & 0,437 \\
\hline Média & 0,43 & 0,37 & 0,42 & 0,45 & \\
\hline
\end{tabular}

Letras minúsculas iguais correspondem a comparação entre doses (colunas) não diferem entre si no teste Tukey ( $\mathrm{P} \leq 0,05)$. Fonte: Autores.

A variável MSR, apresentou 22,17\%; 19,94\%; 20,06 \%; e 22,11\% de matéria de seca (MS), para: 0; 100; 200; e 300 esporos.planta ${ }^{-1}$, respectivamente. Os tratamentos mostraram valores inferiores quando comparados ao valor do tratamento controle. Em relação às cultivares, a $c v$. Gigante Amarelo acumulou 21,98\% de MSR, seguida por Rubi do Cerrado (21,02\% MSR) e Sol do cerrado (20,22\% MSR).

\section{Considerações Finais}

A altura da planta das mudas no tratamento com concentração 0 esporos.planta ${ }^{-1}$ apresentaram maiores valores comparado ao tratamento de 100 esporos.planta ${ }^{-1}$ e tendem a aumentar a partir da concentração de 200 esporos.planta ${ }^{-1}$ com o $^{\circ}$ fungo Gigaspora candida.

Para o número de folhas, as cultivares Gigante amarelo e Sol do cerrado mostram tendência em todas as densidades de FMA testadas. A $c v$. Rubi do Cerrado apresentou o menor número de folhas em todas as doses testadas.

O fornecimento de informações sobre os componentes da fitomassa (ou biomassa) é fundamental, pois através deles pode-se determinar o vigor da muda e viabilizar o desenvolvimento da mesma em condições de campo.

\section{Referências}

Agra, A. G. S. M (2007). Utilização de rizobactérias e micorrizas na produção de mudas de maracujá. Dissertação (Mestrado) - Programa de pós-graduação em Produção Vegetal, Universidade Federal de Alagoas.

Boff, V. L., Mello, A. H. (2009) Seleção e multipicação de fungos micorrízicos arbusculares para produção de mudas para agricultura familiar. Revista Agroecossistemas, 1 (1), 13-13.

Cavalcante, U. M. T., Maia, L. C., Melo, A. M. M., \& Santos, V. F. D. (2002). Influência da densidade de fungos micorrízicos arbuscu lares na produção de mudas de maracujazeiro-amarelo. Pesquisa Agropecuária Brasileira, 37(5), 643-649.

Cavalcante, U. M. T., Maia, L. C., Nogueira, R. J. M. C., \& Santos, V. D. (2001). Respostas fisiológicas em mudas de maracujazeiro amarelo (Passiflora edulis Sims. f. flavicarpa Deg.) inoculadas com fungos micorrízicos arbusculares e submetidas a estresse hídrico. Acta botânica brasílica, 15(3), 379-390.

Embrapa (2018). Produção brasileira de maracujá. Embrapa: mandioca e fruticultura. (INFOTECA-E).

Ferreira, D. F. (2014). Sisvar: a Guide for its Bootstrap procedures in multiple comparisons. Ciência e agrotecnologia, 38(2), 109-112. 
Research, Society and Development, v. 10, n. 2, e47010212672, 2021

(CC BY 4.0) | ISSN 2525-3409 | DOI: http://dx.doi.org/10.33448/rsd-v10i2.12672

Gomes, R. P. (2002). Fruticultura brasileira. (13a ed.).

Hoffmann, L. V., \& Lucena, V. S. (2006). Para entender Micorrizas Asbusculares. Embrapa Algodão-Documentos (INFOTECA-E).

IBGE - Instituto Brasileiro de Geografia e Estatística. Produção Agrícola Municipal (2019): Culturas Temporárias e Permanentes. Produção Agrícola Municipal. Disponível em: https://sidra.ibge.gov.br/tabela/5457.

INMET - Instituto Nacional de Meteorologia (2016). https://www.inmet.gov.br.

Matos, R. M. B., Silva, E. M. R., \& Lima, E. (1999). Fungos micorrízicos e nutrição de plantas. Embrapa Agrobiologia-Documentos (INFOTECA-E).

Portal Tocantins (2019). Governo revitaliza Projeto São João e garante segurança hídrica aos produtores. https://portal.to.gov.br/noticia/2019/4/4/governorevitaliza-projeto-sao-joao-e-garante-seguranca-hidrica-aos-produtores/.

Silva, M. A. D., Cavalcante, U. M. T., Silva, F. S. B. D., Soares, S. A. G., \& Maia, L. C. (2004). Crescimento de mudas de maracujazeiro-doce (Passiflora alata Curtis) associadas a fungos micorrízicos arbusculares (Glomeromycota). Acta botanica brasilica, 18(4), 981-985.

Silveira, A. P. D. D., Silva, L. R. D., Azevedo, I. C. D., Oliveira, E. D., \& Meletti, L. M. M. (2003). Desempenho de fungos micorrízicos arbusculares na produção de mudas de maracujazeiro-amarelo, em diferentes substratos. Bragantia, 62(1), 89-99.

Vitorazi Filho, J. A., Lima, K. B., Freitas, M. S. M., Martins, M. A., \& Olivares, F. L. (2012). Crescimento de mudas de maracujazeiro-doce inoculadas com fungos micorrízicos arbusculares e bactérias diazotróficas sob diferentes doses de fósforo. Revista Brasileira de Fruticultura, 34(2), 442-450. 